\title{
POR UMA EDUCAÇÃO ESTÉTICA NA FORMAÇÃO UNIVERSITÁRIA DE DOCENTES*
}

\author{
Verussi MeLo de AMorim ${ }^{* *}$ \\ Maria Eugênia CaSTANHo ${ }^{* * *}$
}

Poemas inconjuntos (1913-1915)

Não basta abrir a janela

Para ver os campos e o rio.

Não é bastante não ser cego

Para ver as árvores e as flores.

É preciso também não ter filosofia nenhuma.

Com filosofia não há árvores: há idéias apenas.

Há só cada um de nós, como uma cave.

Há só uma janela fechada, e todo o mundo lá fora;

E um sonho do que se poderia ver se a janela se abrisse,

Que nunca é o que se vê quando se abre a janela.

(Fernando Pessoa, Poemas completos de Alberto Caeiro)

RESUMO: É-se professor ao construir-se professor. Considerando a formação docente como um continuum que se faz indefinida e inacabadamente, e não por meio de obtenção de títulos ou licenciatura, a questão que se coloca refere-se à possibilidade de uma educação estética na universidade. Esta pesquisa se sustenta num diálogo teórico, em que estudiosos da educação estética, por meio de entrevistas, tratam da formação docente como um processo (permanente) de descobertas e rupturas. Processo completamente imbricado à subjetividade do docente em formação, delineando uma docência

* $\quad$ Este artigo se baseia em parte da dissertação de Mestrado defendida em março de 2007, no Programa de Pós-Graduação em Educação da Pontifícia Universidade Católica de Campinas (PUC-Campinas), intitulada: Por uma educação estética: um enfoque na formação universitária de professores.

** Mestre em Educação pela Puc-Campinas. E-mail: verussi@gmail.com

*** Doutora em Educação e docente do Programa de Pós-Graduação em Educação da PUCCampinas.E-mail: meu@dglnet.com.br

Educ. Soc., Campinas, vol. 29, n. 105, p. 1167-1184, set./dez. 2008

Disponível em <http://www.cedes.unicamp.br> 
particular, em que cada sujeito faz sua própria história. $\mathrm{O}$ intento da pesquisa é discutir uma proposta de educação estética para a formação universitária de professores, entendendo que a experiência estética pode promover rearranjos subjetivos no universitário, instigando-o a pensar-se e a formar-se sujeito (e dono de sua própria prática), em vez de consumista de modos-de-ser pré-construídos.

Palavras-chave: Educação estética. Arte. Universidade. Formação docente.

\section{FOR AN AESTHETIC EDUCATION IN PROFESSOR TRAINING}

ABSTRACT: One becomes a professor by constructing oneself as a professor. If we consider professor training as an indefinite and unfinished continuum, not as the obtention of diplomas or Licenciatura (teacher credential), the question that arises concerns the possibility of an aesthetic education in universities. This research is grounded in a theoretical dialog, where specialists of Aesthetic Education interviewed by the author consider professor training as a (permanent) process of discovery and rupture. Completely interwoven with the subjectivity of the trained professor, this process delineates a particular teaching, in which each subject makes their own history. The author discusses an aesthetic education proposal for the graduate training of professors that comprehends that aesthetic experiments can promote subjective rearrangements in the students and instigate them to think of themselves and develop as subjects - and owners of their own practice -, not as consumers of ready-made ways-of-being.

Key words: Aesthetic education. Art. University. Teacher training.

\section{Palavras prévias}

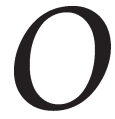

ensaio que ora é feito, neste texto, percorre o mundo externo (a realidade diária, cotidiana, corriqueira de qualquer e toda pessoa), atravessa a concepção de realidade entendendo-a como uma possibilidade de existência artística (como pensar a beleza no mundo), caminha em direção à arte e à maneira como sua fruição pode possibilitar visão mais sensível de coisas/acontecimentos, e desemboca no modo como uma visão pautada sob estas noções e formada sob tais concepções pode conceber uma pessoa sensível ao mundo - externo, interno, inter-relacional - e de que maneira ela pode tornar outras pessoas sensíveis ao mundo. Nesse sentido, discute-se a formação universitária, 
considerando a necessidade de um enfoque sobre questóes que ultrapassam conteúdos específicos e avançam no sentido do sensível, da estética, do conhecimento por intermédio dos sentidos humanos e da reflexão sobre eles. Para tanto, os parceiros desta escrita de agora foram sete professores-pesquisadores brasileiros que estudam a temática educação estética. Inicialmente, a intenção era realizar entrevistas presenciais com cada um, entretanto, isso diminuiria o campo de exploração, posto que se restringiria ao estado de São Paulo. Assim, optou-se pela versão cibernética, a fim de ampliar a abrangência da discussão e poder discutir com docentes de variados estados brasileiros. ${ }^{1}$ Dessa forma, foram enviados um convite e a apresentação da proposta de pesquisa por meio de e-mails, conseguidos por intermédio do Currículo Lattes de cada docente. Após o aceite e o pronto e carinhoso acolhimento dos docentes, ${ }^{2}$ foi enviado um questionário ${ }^{3}$ com questões gerais - iguais para todos os participantes - e uma questão específica sobre uma importante obra do docente. O contato foi iniciado em meados de 2006 e as respostas foram recolhidas, salvo poucas exceções, em torno de uma a duas semanas após o envio do questionário.

$\mathrm{O}$ que fica de todas as respostas oferecidas em diálogo à pesquisa é seu caráter de registro, impresso, que vence o tempo e o espaço, caminha a lugares em que não estamos, atravessa o momento de agora e se perpetua a tempos futuros. Junto com tais respostas, acrescemos nossas palavras e, então, seguimos delineando caminhos.

In-sensibilização contemporânea: um ponto de partida

(...) o paciente em crise é o próprio mundo... Os novos sintomas são fragmentação, especialização, hiperespecialização, depressão, inflação, perda de energia, jargões e violência. Nossos prédios são anoréxicos; nossos negócios, paranóicos; nossa tecnologia, maníaca. (Robert Sardello, 1986)

Sem a intenção de enfadar o leitor com uma exaurida exposição da terminologia do neoliberalismo ou com termos congêneres, como pós-modernidade, e igualmente sem a pretensão de esgotar todas as fontes referentes a este tema, faz-se fundamental a explanação das repercussões/implicações destes nos tempos atuais, e o contorno da sociedade (de) que resultou. 
Freitas (2005, p. 22), ao tratar do discurso pós-moderno, analisa a maneira como este vem apregoando formas individuais de luta política, ao desinstalar a esperança do indivíduo:

Para o cidadão comum, a luta pela sobrevivência diária retira-o do envolvimento e das preocupações com o outro, com as instituiçôes, com os valores, com os princípios, com o coletivo. Dessa forma, enfraquece movimentos sociais, instâncias coletivas de luta, associações de interesses, partidos, enfim, fragmenta e mergulha o indivíduo em um profundo narcisismo.

A instalação da incerteza no indivíduo, resultante deste movimento de descrédito em relação aos movimentos coletivos, que não ganham repercussão social ou viram um grande debate político, serve à manutenção do status quo, em que, realmente, cada indivíduo não tem forças suficientes para transformar a realidade, inserindo-se nela. Dessa maneira, permanece à margem, na ilusão de participação. Em palavras de Freitas (idem, ibid.):

A incerteza cria um campo tão aversivo, que o indivíduo sente que é melhor não pensar nele e se concentrar no agora, com isso, abre-se mão do futuro e ele termina sendo planejado por outros, sem obstáculos. A impotência do indivíduo em relação ao futuro é, ao mesmo tempo, a plena potência do capital para pensar seu futuro com total ausência de limites, com total flexibilidade e liberdade (liberdade aqui entendida como possibilidade de realização de valor).

Bauman (2001) aproxima-se deste aspecto ao discutir, utilizando-se de termos metafóricos, a fluidez e a solidez dos discursos da contemporaneidade, propondo a idéia de que nem sempre o sólido, fixado em superfície estável, é ruim, na medida em que nem sempre o fluido - móvel, inconstante - é a melhor característica para se tratar dos movimentos humanos. Contrariando a noção de que, à primeira vista, poder-se-ia ter destes termos, atribuindo-lhes juízos de valor (fluidez é algo positivo, ao passo que tudo o que é sólido, fixo, imutável, é algo a ser revisto e não seguido), Bauman analisa-os, assinalando o risco da apropriação ingênua e irrefletida dos discursos atuais que pregam, por exemplo, a fluidez como algo positivo, desconsiderando seus aspectos desestabilizadores das organizações coletivas. Neste aspecto, o autor assinala que: 
O "derretimento dos sólidos", traço permanente da modernidade, adquiriu, portanto, um novo sentido e, mais que tudo, foi redirecionado a um novo alvo, e um dos principais efeitos desse redirecionamento foi a dissolução das forças que poderiam ter mantido a questão da ordem e do sistema na agenda política. (2001, p. 12)

A (pós-)modernidade é marcada por este discurso amorfo, em que as idéias fluidamente mudam de posição, amoldando-se a interesses políticos, cujo pano de fundo são idéias bastante solidificadas.

Hillman (1993) considera a atualidade segundo a idéia de que o mundo adoeceu, perdeu sua relação direta com as coisas naturais, tem afastado o homem do contato intersubjetivo e com o ambiente que o rodeia, cercado que está de um aparato tecnológico sofisticado que o preserva de, por exemplo, caminhar, explorar a trilha de sua casa ao mercado, mirar os olhos dos transeuntes. O autor confere especial atenção à atividade de caminhar, que é, em essência, uma atividade primordial, sob a qual, inclusive, a polis foi fundada: "Uma cidade é o vaivém de uma multidão comum nas ruas" (Hillman, 1993, p. 52). O autor analisa a interface entre o mundo citadino e a construção subjetiva do homem atual, ao considerar que a lógica sob a qual se pauta a economia mundial resulta na produção de uma humanidade frágil em sensibilidade, fragmentada, sem valores sólidos ou firmes.

A maneira como a sociedade e o mundo se organizaram, com a investida neoliberal nos modos de produção, produziu o homem contemporâneo, marcadamente (e por marcas entendamos signos incorporados ou estampados sobre a pele) regido por uma lógica consumista e da aparência. Christopher Lasch (1986) refere-se à sociedade programada, em que os modos de se vestir, se comportar, se alimentar, etc. são "ensinados" pela mídia, aliada a grandes corporações industriais. Neste sentido, a formação do homem dá-se nivelando sua psique ao mínimo necessário, ao mínimo possível para que haja o máximo de intervenção mercadológica sobre si. Daí a terminologia "mínimo eu”. Em palavras de Duarte Júnior (2003, p. 20): “(...) em tal sociedade programada, resta-nos apenas desenvolver o 'mínimo eu', sem grandes apegos a valores e crenças e flexível o suficiente para mudar de opinião e de estilo ao sabor das alterações da moda".

Avançando a discussão para esferas globais, a influência de uma cultura dominante sobre as demais, num comércio cultural homogeneizante, 
produzirá (e tem produzido) uma padronização em torno do consumo. A presença de fast-food, acelerando nossa alimentação, que deveria ser um momento de encontro e convívio (inimigo sério do projeto de uma sociedade homogênea), a etiquetação de nossos corpos, com marcas-símbolo de status e, portanto, de inclusão neste mundo veloz, estas são, para citar apenas algumas, características da atualidade, que provocam o descrédito pelo durável, pelo valor solidamente ancorado em princípios e em ética. Imersos nesta factual realidade,

(...) os humanos vão perdendo a face sob penteados e cosméticos [enquanto] os carros vão ganhando nomes e dianteiras cada vez mais característicos, expressōes mais personalizadas (...). Mas a cara do motorista dentro do carro é geralmente vazia, congelada atrás do pára-brisa. Cinto afivelado, portas trancadas, toca-fitas ligado, olhos fixos para a frente, passivamente registrando o movimento de objetos lá fora (...). (Hillman, 1993, p. 52)

A quase invisibilidade do homem, no que se refere a suas particularidades, é sobreposta pela visibilidade de seus pertences, das insígnias que o identificam (e o in-distinguem, na mesma medida). O homem contemporâneo deve ser (e, obedientemente, tem sido) este indivíduo assujeitado: individualista em seus projetos, a fim de inserirse na esfera competitiva; individual entre seus pares, freqüentemente marcado pelo isolamento de seu trabalho e de suas funções monólogas.

Paradoxalmente, tal como os tempos atuais, o homem, hoje, empresta sua unicidade ao coletivo que, na contramão epistemológica, não agrega, mas, em nível intenso, des-integra a própria humanidade. Em essência o homem está fragmentado, por suas atividades, pela maneira dissociada com que a realidade o aprisiona (em gabinetes de trabalho ou sessôes com divisórias, no gigantismo das cidades que o coloca em seu automóvel, isolante de estímulos externos etc.), e a falsa integração dá-se por intermédio de meios que mais ainda o afastam de si mesmo.

A ciência concentra determinados saberes como relevantes, à medida que descarta outros: o racionalismo privilegia a mente, em detrimento de saberes da sensibilidade. O conhecimento local, o senso comum, o saber advindo da experiência cotidiana têm seu lugar não legitimado, em nome de saberes considerados universais - o que significa corresponder ao universo da ideologia dominante. A razão, privilegiada e tornada central na concepção da ciência, provoca o apartamento do sensível no homem: 
É ficando enclausurada na consciência pura que, pouco a pouco, a razão se distancia do mundo circundante, torna-se assunto de especialistas ou, ainda, serve de garantia a todos os processos de organização e de gestão que caracterizam a tecnoestrutura contemporânea. (Maffesoli, 1998, p. 34)

$\mathrm{Na}$ abordagem que Shiva (2003), faz em relação à silvicultura e à agricultura, nota-se justamente este ponto - o do apartheid entre as culturas local e mercadológica/industrial, cada qual com seus sistemas (incompatíveis) de saber. Os saberes locais, de domínio e relação com a natureza, com o ambiente vivente, o saber sensível da população é desacreditado, posto que não serve ao interesse industrial. Nesse sentido, parece haver um deslocamento do saber in-corpo-rado, construído a partir da relação direta e sensível do homem com o mundo, de seu respeito para com a natureza, para um saber menta-lizado, que pensa cifras e lucros. Hillman (1993, p. 127) adverte-nos para a necessidade de beleza que o homem tem, pontuando que:

(...) se reconhecemos que a necessidade de beleza deve ser satisfeita, mas que a natureza cênica e física não é o único lugar onde ela pode ser satisfeita, resgataríamos a alma, percebendo que aquilo que acontece com ela é menos dado do que feito - feito por nosso trabalho com ela no mundo real, ao fazer com que o mundo real reflita a necessidade de beleza da alma.

É deste lugar, em favor da apreciação da experiência, do elogio do sensível, que este texto pretende iniciar o vislumbre de uma educação na contramão daquilo a que vimos assistindo. Uma educação que não se esqueça de que, "além ou aquém da racionalização da fé, há a experiência vivida fundando a vida corrente" (Maffesoli, 1998, p. 172).

Arte como leitura de mundo

(...) Só que ninguém poderá ler no esgarçar destas nuvens a mesma história que eu leio, comovido. (Ferreira Gullar, 1975)

A leitura do mundo, segundo Paulo Freire (2002), é precedente à das palavras, que acontece quase como conseqüência daquela. Ao narrar sua experiência de alfabetização, Freire fala do seu encantamento em desvendar o significado das letras, sentado no chão do quintal de casa, rodeado por mangueiras, ao som dos pássaros: "O chão foi meu 
quadro-negro; gravetos, o meu giz" (p. 15). Leitura seria, portanto, de acordo com estas consideraçôes, o modo particular com que o sujeito apreende o mundo, a realidade que o circunda e o contexto no qual está imerso. Outra consideração, também, pode-se fazer sobre a experiência narrada por Freire (op. cit.): ele pôde transformar o chão no qual pisava na lousa em que se desenham letras; pôde olhar para gravetos, pedaços pequenos e finos de madeira, e imaginá-los giz, instrumento de escrita. Sua visão transcendeu a real significação das coisas e deu-lhes outro sentido. Leitura é isto: olhar o habitual e vê-lo diverso. Esta capacidade de voltar o olhar ao objeto, re-significando-o, é o princípio da arte:

A arte aumenta "a dificuldade e a duração da percepção", descreve o objeto "como se o visse pela primeira vez" (como se não existissem já fórmulas para o descreverem) e o fim da imagem não é tornar mais próxima da nossa compreensão a significação que veicula, mas criar uma percepção particular do objeto. (Eco, 1997, p. 70)

O processo de desarticulação da percepção - característica das artes, em geral - é possível em decorrência da particularidade proposta pela arte: transgressão do código vigente. Eco, ao se referir à mensagem com função estética, afirma o caráter de ambigüidade que deve existir, a fim de pôr o código em desordem, possibilitando um conseqüente choque de compreensão no fruidor e tornando não imediata a interpretação do visto. Sobre isso Eco (1997, p. 64) discorre:

O efeito de estranhamento ocorre desautomatizando-se a linguagem: a linguagem habitua-se a representar certos fatos segundo determinadas leis de combinação, mediante fórmulas fixas. De repente, um autor, para descrevernos algo que talvez já vimos e conhecemos de longa data, emprega as palavras (...) de modo diferente, e nossa primeira reação se traduz numa sensação de expatriamento, numa quase incapacidade de reconhecer o objeto (...).

A intenção, na obra de arte, se assim se pode falar, não é a do autor, mas a de quem a frui: "O objetivo da imagem é criar uma percepção particular do objeto, criar uma visão e não o seu reconhecimento" (Chklovski, 1917, p. 50). Esta sensação de estranheza diante do já conhecido provoca, no fruidor, a necessidade de reconsiderar a mensagem, transportando-a a um novo lugar, de onde possa mirá-la. Desse lugar novo é que emerge um novo homem, pois o objeto descrito - e previamente conhecido - tornou-se uma descoberta surpreendente: um 
objeto visto sob ângulo jamais suposto. Neste aspecto, a arte possibilita ao sujeito viver sentimentos e experienciar sensaçôes que em seu cotidiano não o faz, em razão da organização prévia das coisas. Por exemplo, ao assistir a uma peça teatral dramática, o sujeito chora a dor do personagem, sobressalta-se com as cenas, assusta-se e freqüentemente se entristece ou se irrita com enredo ou o destino de seu personagem eleito. Essas sensaçôes levam o sujeito a outra esfera de vivências e o ensinam a viver as dores (neste caso específico do drama) que, em sua vida diária, não vive. Essas dores o ensinam sobre si. Eco (2001, p. 2), ao referir-se à Literatura, afirma:

A função das narrativas imodificáveis é justamente essa: contrariando nosso desejo de mudar o destino, nos fazem experimentar a impossibilidade de mudá-lo. E, assim, qualquer que seja a história que elas contem, contarão também a nossa, e é por isso que as lemos e as amamos. Necessitamos de sua severa lição "repressiva”. (...) As histórias "já feitas" nos ensinam também a morrer. Creio que essa educação para o fado e para a morte seja uma das principais funçōes da Literatura.

A fruição de arte é, pois, um momento que possibilita quebra de sentidos e construção de novos, na medida em que permite a transcendência da realidade, convidando o sujeito a inaugurar a visão das coisas. Em se tratando, especificamente, da Literatura, cita-se Iser (1996, p. 11): "Mesmo quando um texto literário não faz senão copiar o mundo presente, sua repetição no texto já o altera, pois repetir a realidade a partir de um ponto de vista já é excedê-la". Nesta direção, a leitura de mundo, provocada pela desestabilização da fruição da obra artística, dá-se quando o sujeito, forçado pela necessidade de organizar a experiência caótica que a arte lhe proporcionou, reformula sua percepção, conferindo novos sentidos ao vivenciado.

\section{Explicitando conceitos}

O poeta aumenta o mundo, agregando ao real, que está aí por si mesmo, um continente irreal. Autor vem de auctor, o que aumenta. (Ortega y Gasset, 1925)

Entendemos que a dimensão estética se refere ao desenvolvimento do gosto pelas artes, ao desenvolvimento da capacidade de vincular-se 
artisticamente com a vida. Trata-se de uma atividade original do espírito ligado ao belo, ao agradável, à fruição, às emoções, mas ligada também a outros aspectos da vida, porquanto é a totalidade das faculdades humanas que estão presentes no ato de criação ou da apreciação. Leonardo da Vinci já advertia que "la pittura e cosa mentale". Francastel (1973) apontou que não é justo dizer que a ciência tem leis que a arte transfere a seu domínio porque não é a ciência, e sim o mundo exterior, que tem suas leis. Mostra ele que a pessoa sensível sabe que a fruição de uma obra de arte requer tempo e esforço e jamais se trata de descobrir, de uma só vez, a totalidade de aspectos nela incluídos. A arte não é parte de um domínio separado do domínio intelectual. A produção artística é regida por leis gerais comuns a todas as outras formas de conhecimento e constitui uma modalidade do saber, já que se realizam nela processos mentais de raciocínio, memória, imaginação, abstração, comparação, generalização, dedução, indução, esquematização. John Dewey (1980) reivindica para o artista o status de ser pensante já que ele seleciona, simplifica, classifica, abrevia e condensa de acordo com seu desejo. Através da dimensão estética podemos entrar muito mais profundamente no entendimento de nossa cultura e sermos sujeitos muito mais ativos na sua elaboração. $\mathrm{E}$ isto porque esta dimensão implica um código de símbolos ao mesmo tempo sensíveis e intelectuais. Nossa civilização tem preterido o desenvolvimento dos sentidos. Vejamos:

A função da linguagem é significar e comunicar os significados, mas nós, homens modernos, reduzimos o signo à mera significação intelectual e a comunicação à transmissão de informação. Esquecemos que os signos são coisas sensíveis e que operam sobre os sentidos. O perfume transmite uma informação que é inseparável da sensação. O mesmo sucede com o sabor, o som e as outras impressões sensoriais. O rigor da "lógica sensível" dos primitivos nos fascina por sua precisão intelectual; não é menos extraordinária a riqueza das percepçôes: onde um nariz moderno não distingue senão um cheiro vago, um selvagem percebe uma gama definida de aromas. $\mathrm{O}$ mais assombroso é o método, a maneira de associar todos esses signos até tecer com eles séries de objetos simbólicos: o mundo convertido numa linguagem sensível. Dupla maravilha: falar com o corpo e converter a linguagem num corpo. (Paz, 1979, p. 17-18)

Essa visão se articula com a idéia de que o desenvolvimento da dimensão estética haverá de chamar a atenção para o permanente papel transformador que as criações culturais têm. Snyders (1974) mostra 
que aqueles que determinaram mudanças radicais no pensamento e na ação são os que assimilaram mais profundamente a cultura existente, penetraram nos elementos revolucionários inclusos nas obras. Entendemos a arte como "informante do real" (Castanho, 1982) e vemos a possibilidade de que os jovens apreendam sua importância gnosiológica, em nada inferior às outras formas mais valorizadas pela Academia.

\title{
A estética da professoralidade ${ }^{4}$
}

\author{
Inquirido sobre a raça, respondeu: \\ - A minha raça sou eu, João Passarinheiro. \\ Convidado a explicar-se, acrescentou: \\ - Minha raça sou eu mesmo. A pessoa é uma \\ humanidade individual. \\ Cada homem é uma raça, senhor polícia. \\ (Mia Couto, 1990)
}

Adentrando a Academia, passeando por seus corredores e arredores, iremos chegar à figura do professor. Seja em sala de aula, na de professores, a caminho da saída, lá está ele, carregando expectativas sobre si, sobre sua fala, sobre a condução de uma discussão, sobre, inclusive, sua vida particular. Uma série de expectativas e prévias concepções sobre a atitude, a postura, a direção e o tratamento que o professor dará em suas aulas pululam os pensamentos dos estudantes. Mas... de que maneira aquele homem/mulher, jovem ou não, com ou sem filhos, casado/a ou divorciado ou solteiro ou qualquer outro modo de interrelação, de que maneira esta pessoa se torna professor?

A literatura está recheada de histórias que contam a passagem de um estado de ser a outro, de metamorfoses que os protagonistas sofrem no decorrer de suas vidas e que os marcam profunda e significativamente. Dr. Jekyll e Mr. Hyde, por exemplo, personagens da fantástica história ${ }^{5}$ de Robert Louis Stevenson, revelam-nos, de forma quase incrível, a maneira como um homem se metamorfoseia noutro que, no fim das contas, é ele mesmo. Gregor Samsa, transformado em inseto n'A metamorfose kafkiana, parece, a partir de então, viver de maneira mais fiel aos infortúnios de sua vida familiar - como um estorvo sem valor. Outras tantas metamorfoses, não descritas sob a lente do fantástico, mas sob a escrita romântica ou intimista, são igualmente metáforas 
do modo como o ser humano vai se transformando, recriando-se incansável e interminavelmente. Momentos de epifania, de insights, são freqüentes na literatura, pontos-chave da trama, que se vai desenrolando e se desenvolvendo em torno deles.

Todo acontecimento no mundo é um potencial de acontecimento no homem. Cecília Meireles escreveu sobre uma folha ${ }^{6}$ que caía, tornando aquele momento - natural e cotidiano - algo sobre o qual detemos o olhar ao lê-la. Aquele foi, certamente, um momento sobre o que à escritora pareceu importante falar. Estas como tantas outras experiências vão, diariamente, constituindo-nos. Haverá um modo de precisar o momento em que, em se pensando na educação, uma pessoa se torna professor? Será que, ao receber o título de licenciatura, o estudante, a partir de então, torna-se professor? Ou será que se torna ao ser contratado por uma instituição de ensino? De que maneira medir, apontar, demarcar o momento em que esta constituição se dá? Será algo instituído, alguma agência exterior ao sujeito outorgando-lhe direitos; ou será algo construído, que se vai fazendo, montando e se desmontando de acordo com as vivências de cada sujeito? Segundo Pereira (1996, p. 15-16), ser professor "(...) não é vocação, não é identidade, não é destino. É produto de si. E a busca pela formação acadêmica caminha no sentido de buscar modos de apropriação e ativação dessa marca em consonância com as singularidades que constituem o campo de existencialização do indivíduo".

A formação não é algo que se recebe, mas que se faz num processo ativo que requer o envolvimento, a aproximação e a mediação de outros (Pereira, 2003, no prelo). Formar-se é constituir-se num processo, implicar-se nele. O texto de Pereira aponta a maneira como algumas teorias têm tomado este lugar, enviesando a formação, por abafá-la em seu caráter processual, delegando, exclusiva ou predominantemente, a teorias (e teóricos) a função de formadores de professores. Diante disso, a experiência e a vivência individual do docente distanciam-se de sua formação, sendo desconsideradas como imprescindíveis na constituição do sujeito. A titulação acadêmica ou o contrato institucional, que designam um nome à profissão do sujeito, não são garantia de constituição professoral; as marcas produzidas no sujeito (Pereira, 1996) o são. Docente é "aquele que está desenvolvendo um processo de ensinar” (Rios, 2003, p. 53), é no seu exercício que o professor se vai constituindo. Rios se detém no significante docente, conjugado no particípio presente, para pensar a 
docência como este ser em exercício - um ensinante. A autora põe-se (e a nós) uma questão: "Como os saberes da docência podem auxiliar o professor na direção de uma atuação competente?” (p. 56). Numa versão reformulada e, quiçá, complementar desta questão, coloca-se outra sobre formação de professores, sobre a maneira como, na formação universitária - foco deste trabalho - poderão ser possibilitadas/promovidas experimentações de si. Nesse sentido, lida-se não com o intelecto, com uma educação conceitual, de idéias, racional, mas com maneiras de fruição estética. Em palavras de Rios (2003, p. 45):

É preciso resgatar o sentido da razão que, como característica diferenciadora da humanidade, só ganha sua significação na articulação com todos os demais "instrumentos" com os quais o ser humano se relaciona com o mundo e com os outros - os sentidos, os sentimentos, a memória, a imaginação.

A maneira como esta afirmação pode se transformar em proposta de uma educação voltada aos sentidos, ao sensível, à dimensão estética do homem é o grande e nodal ponto deste trabalho. De que modo(s) a educação se voltará a este aspecto humano - estético - num momento em que a razão (ainda) é a razão-de-ser do ensino? Talvez possamos começar a fazer ensaios de proposta, até conseguirmos vislumbrá-la e praticá-la!

Nas entrelinhas: por uma educação estética ${ }^{7}$

O que você acha que é um artista? Um imbecil que, se é pintor, só tem olhos? (...). Pelo contrário, ele é também um ser político, constantemente atento aos dilacerantes, ardentes ou doces acontecimentos do mundo (...). Não, a pintura não é feita para decorar apartamentos (...). É um instrumento de guerra ofensiva e defensiva contra o inimigo. (Pablo Picasso, 1945)

A reflexão feita aponta para a preocupação com a dimensão estética na educação, entendida, na verdade, como uma dimensão humana que tem sido relegada nas instituiçôes escolares, em nome de uma educação do intelecto. Educação estética refere-se à atitude do sujeito perante o mundo, o estabelecimento de uma relação sensível, de beleza, de harmonia com o mundo - relação que está se ampliando para 
outros campos que não somente o da arte-educação (Duarte Júnior, 2006). A educação, em palavras de Marly Meira (2006), começa a se decepcionar "com suas parceiras racionalistas, a Ciência e a Tecnologia", pois estas "não admitem que o campo do sensível não seja redutível à linguagem verbal e à matemática, nem que a invenção, a criatividade, o sonho, o devaneio, a fantasia façam parte das operaçôes mentais do mundo da consciência”. Dialogando nesta direção, Rios (2003, p. 97) aponta que "a sensibilidade e a criatividade não se restringem ao espaço da arte. Criar é algo interligado a viver, no mundo humano. A estética é, na verdade, uma dimensão da existência, do agir humano". No ensino, de forma geral - tanto em escolas quanto em universidades -, há o privilégio da racionalidade ocidental, que torna alunos e professores pessoas eminentemente voltadas ao saber teórico, encerrado em livros didáticos, em aulas-padrão, em conteúdo não renovado. Sobre este ponto, Luciana Loponte (2006) aponta a crença no poder da ciência, instituída como aquela responsável e capaz de encontrar $a$ verdade, considerando incômodos quaisquer desvios, erros ou descontinuidades. Em suas palavras,

a universidade ainda é feita de 'homens sérios'. E a formação docente também, quando almeja a modelos ou lista de competências a serem seguidas. A universidade precisa de mais estética, mais arte, mais desafios às verdades únicas.

A arte ${ }^{8}$ portanto, não seria apenas mais uma disciplina curricular, mas uma maneira por meio da qual se poderá chegar a esferas outras do humano não alcançadas pelo ensino tal como veiculado hoje nas escolas. O aluno seria, tal como os olhos de Paulo Freire, capaz de mirar o chão e vê-lo lousa, sobre a qual desenhar seu próprio percurso, sua história. A arte educa parte adormecida do homem. Duarte Júnior (2004, p. 72) discorre a este respeito, ao dizer que a arte

(...) pretende ser uma maneira mais ampla de se abordar o fenômeno educacional considerando-o não apenas como transmissão simbólica de conhecimentos, mas como um processo formativo do humano. Um processo que envolve a criação de um sentido para a vida, e que emerge desde os nossos sentimentos peculiares.

Assim, a arte seria uma provocadora de sentimentos, na medida em que age sobre os sentidos humanos, e, dessa maneira, portanto, seria educadora. Porque possibilitaria ao sujeito conhecer as nuances das coisas cotidianas, por meio de seu próprio corpo, encarnando a experiência, 
incorporando os sentidos, fazendo da vida algo contextual, parte de si. Apreender o mundo, ingenuamente, por intermédio da ótica de outrem é o meio contra o qual uma educação que se pretenda estética luta, ao reivindicar que o sensível se faça janela por onde o aluno possa ver-se, aos seus companheiros e ao mundo. Como disse Meira (2006), "criar não é sinônimo de solução de problemas, mas a capacidade de tecer questões em composição, perceber como realizar algo compatível com a compreensão de que estamos interferindo na teia da vida, redimensionando-a sob modo próprio". É como seguir os mandamentos dos modernistas ${ }^{9}$ e agir como antropófagos: devorar o que é estrangeiro, para digeri-lo e, então, reformulá-lo como algo próprio. Entendendo por estrangeiro aquilo que vem de fora, de outro, e que nos é importante/interessante conhecer; mas digeri-lo, eis o fundamental: tornar o conhecimento algo próprio e não meramente ingerido. Com isso, pretende-se que a educação não se fixe no conhecimento transmissivo (se é que se pode assim chamá-lo), repassando informações, encadernando-as e cristalizando-as no entendimento dos alunos. $\mathrm{O}$ aluno precisa inventar o conhecimento, produzir suas crenças, fabricar suas convicções, como adverte Marcos Villela Pereira (2006). Pretende-se, como ressalva Meira (2006), que o conhecimento nasça de "atitudes poéticas diante das informações, da crítica que inclui a diversidade e a simultaneidade no aporte das informações”. O pilar básico de uma proposta de educação estética é a oferta, pela escola, de experiências sensíveis aos alunos, como sugere Duarte Júnior (2006), ou como o faz Meira (2006), que pensa na "educação estética como guardiã de nossa atitude poética ante o que experimentamos, ao aprender o que se passa conosco diferente a cada momento". A autora completa:

Lamentavelmente, a esteticidade cotidiana está poluída pelo marketing e pelo uso inescrupuloso dos valores da beleza e da percepção. Como nos vemos pelo outro, como somos acariciados ou maltratados pelo outro? Como dar qualidade ao que somos ao nos relacionarmos com o que existe e se mostra a nós, aliando a superfície à profundidade mais ampla que a contém? Se pensarmos assim, há estéticas que transcendem o vivido e tocam no sagrado que nos constitui.

Do encontro com as falas dos docentes entrevistados, a proposta que se pode vislumbrar sustenta-se na arte como estimuladora de experiências estéticas, provocando os sentidos do sujeito, convidando-o a ver o mundo com um olhar inaugural, porque re-novado. Proporcionar 
experiências estéticas por meio da arte, em cursos universitários, poderia ser um meio a partir do qual seria possível despertar o sensível nos futuros docentes - pessoas que trabalharão com a arte de ensinar, lidando, diretamente, com a formação humana de alunos. Por meio de experiências estéticas refletidas (e não meramente proporcionadas, sem um enfoque reflexivo e uma discussão pertinente e profunda), com arte, os alunos iriam aproximando-se do universo sensível, podendo estabelecer um elo entre si e sua própria subjetividade. À medida que iria se reconhecendo como um sujeito autor de sua própria história, conhecedor de sua maneira de olhar o mundo, tornar-se-ia cônscio de sua função e do lugar como partícipe na construção do mundo. Neste sentido, o docente que se faz far-se-ia, também, o sujeito criador (e dono) de seu modo de olhar e fazer as relações humanas, o mundo, a educação.

É por esta dimensão estética - humana - que as vozes deste trabalho se fazem verbo e se pretendem audíveis no campo educacional. Para que a educação faça, como nos lembra Pereira (2006), como o Barão de Munchausen: puxe-se pelo próprio cabelo e se desenterre!

\section{Recebido em novembro de 2006 e aprovado em março de 2008.}

\section{Notas}

1. Os estados aos quais pertencem os docentes entrevistados são: São Paulo, Minas Gerais, Rio Grande do Sul e Santa Catarina. O acesso aos docentes deu-se, inicialmente, por obras conhecidas (livros ou por meio de apresentação em congressos, momento a partir do qual se buscou contato com eles) e indicaçôes de outros docentes-pesquisadores da área.

2. É preciso que se ressaltem os percalços da pesquisa, afinal "nem tudo são flores": houve dois docentes contatados, das regiōes Nordeste e Sudeste, cuja participação na pesquisa não foi possível, ainda que tenham respondido, positiva e entusiasticamente, aos e-mails, aceitando o convite. Contatos posteriores foram realizados, após o que, com a urgência do tempo cronológico do PPGE, foi inevitável cessar a investida. Ficaram a curiosidade do diálogo e o pesar de não tê-los aqui.

3. Na dissertação, disponível em <http://www.bibliotecadigital.puc-campinas.edu.br/tde_ busca/index.php>, encontram-se os questionários na íntegra.

4. Marcos Villela Pereira (1996) produziu, no doutorado em Supervisão e Currículo da PUCSP, a tese intitulada $A$ estética da professoralidade - um estudo interdisciplinar sobre a subjetividade do professor, na qual baseei minhas consideraçôes.

5. Referência à célebre obra intitulada, em português, $O$ médico e o monstro.

6. "O vento voa,/ a noite toda se atordoa,/ a folha cai./ Haverá mesmo algum pensamento/ sobre essa noite? sobre esse vento?/ sobre essa folha que se vai?” (Epigrama n. 9). 
7. Este tópico pretende promover uma conversa entre os docentes entrevistados (por meio de correspondência eletrônica) na pesquisa, bem como algumas de suas produções escritas, a fim de delinear possibilidades de uma proposta de educação estética na universidade.

8. A educação estética abrange a arte-educação (ensino de arte nas escolas), sem se deter nela. Refere-se a um tipo de relação mais harmoniosa e respeitosa do homem com a natureza, com o saber advindo dos sentidos. Há ramificaçóes, por exemplo, para o campo da Educação Ambiental, Educação Física etc.

9. Referência à Semana de Arte Moderna, acontecida em São Paulo, em 1922, quando grandes nomes do cenário artístico brasileiro, em favor de uma arte nacional, lançaram o Manifesto Modernista, repudiando estrangeirismos.

\section{Referências}

BAUMAN, Z. Ser leve e líquido. In: Bauman, Z. Modernidade líquida. Trad. Plínio Dentzien. Rio de Janeiro: Zahar, 2001.

CASTANHO, M.E.L.M. Arte-educação e intelectualidade da arte. 1982. Dissertação (Mestrado) - Faculdade de Educação, Universidade Estadual de Campinas, Campinas.

CHKLOVSKI, V. A arte como procedimento. 1917. In: EIKHENBAUn, B. et al. Teoria da literatura: formalistas russos. Porto Alegre: Globo, 1973. p. 39-56.

DEWEY, J. A arte como experiência. São Paulo: Abril, 1980. (Os Pensadores).

DUARTE JÚNIOR, J.-F. O sentido dos sentidos: a educação (do) sensível. 2. ed. Curitiba: Criar, 2003.

DUARTE JÚNIOR, J.-F. Por que arte-educação? 15. ed. São Paulo: Papirus, 2004.

DUARTE JÚNIOR, J.-F. Entrevista concedida à pesquisadora Verussi Melo de Amorim e registrada em gravador digital portátil, em 11 de abril de 2006.

ECO, U. A mensagem estética. In: Eco, U. A estrutura ausente. São Paulo: Perspectiva, 1997. p. 51-66.

ECO, U. A literatura contra o efêmero. Folha de S. Paulo, São Paulo, 18 fev. 2001, Caderno "Mais".

FRANCASTEL, P. A realidade figurativa. São Paulo: Perspectiva, 1973.

Educ. Soc., Campinas, vol. 29, n. 105, p. 1167-1184, set./dez. 2008 
FREIRE, P. A importância do ato de ler: em três artigos que se completem. 43. ed. São Paulo: Cortez, 2002. 87p.

FREITAS, L.C. Uma pós-modernidade de libertação: reconstruindo esperanças. Campinas: Autores Associados, 2005.

HILlmAN, J. Cidade e alma. Trad. Gustavo Barcellos e Lúcia Rosenberg. São Paulo: Nobel, 1993.

ISER, W. $O$ ato da leitura: uma teoria do efeito estético. Trad. Johannes Kretschmer. São Paulo: Editora 34, 1996. 192p. v. 1.

LASCH, C. O minimo eu: sobrevivência psíquica em tempos difíceis. São Paulo: Brasiliense, 1986.

LOPONTE, L.G. Entrevista concedida, por correspondência eletrônica, à pesquisadora Verussi Melo de Amorim, em 20 de maio de 2006.

MAFFESOLI, M. Elogio da razão sensivel. Trad. Albert C. M. Stuckenbruck. Petrópolis: Vozes, 1998.

MEIRA, M. Entrevista concedida, por correspondência eletrônica, à pesquisadora Verussi Melo de Amorim, em 19 de maio de 2006.

PAZ, O. Conjunções e disjunçôes. São Paulo: Perspectiva, 1979.

PEREIRA, M.V. A estética da professoralidade: um estudo interdisciplinar sobre a subjetividade do professor. 1996. Tese (Doutorado em Supervisão e Currículo) - Pontifícia Universidade Católica de São Paulo, São Paulo.

PEREIRA, M.V. Traços de fundamentalismo pedagógico na formação de professores. 2003. (no prelo).

PEREIRA, M.V. Entrevista concedida, por correspondência eletrônica, à pesquisadora Verussi Melo de Amorim, em 19 de junho de 2006.

RIOS, T.A. Compreender e ensinar: por uma docência da melhor qualidade. 4. ed. São Paulo: Cortez, 2003.

SHIVA, V. Monoculturas da mente: perspectivas da biodiversidade e da biotecnologia. São Paulo: Gaia, 2003.

SNYDERS, G. Para onde vão as pedagogias não-diretivas?. Trad. Ruth Delgado. Lisboa: Moraes, 1974. 